\title{
TEMPO, ESPAÇO E GEOGRAFIA - UM ENSAIO
}

\author{
Roberto Lobato Corrêa
}

Universidade Federal do Rio de Janeiro - UFRJ

\begin{abstract}
7 empo e espaço são elementos para a existência de processos e formas tanto criados pela natureza como pela ação humana. Sem tempo e espaço nada existe ou se reproduz. Ambos, tempo e espaço, têm sido objetos da física, filosofia e de outros campos do conhecimento, tendo, no entanto, recebido uma relativamente pequena atenção entre os geógrafos, a despeito da superfície da Terra, morada do Homem, ser uma notável expressão da ação do tempo e do espaço. O presente ensaio procura ressaltar algumas conexões entre tempo, espaço e geografia, estando apoiado na literatura produzida muito particularmente pelos geógrafos. Trata-se, portanto, de um ensaio direcionado sobretudo aos geógrafos.
\end{abstract}

\section{Tempo e espaço - Um esquema}

A figura 1 descreve um conjunto vertical e horizontal de conexões entre tempo e espaço. O esquema descreve tanto os desdobramentos a partir do tempo como do espaço (vertical) e as expressões resultantes das relações entre tempo e espaço (horizontal). Estas indicam como há uma unidade entre tempo e espaço manifesta em pares. 


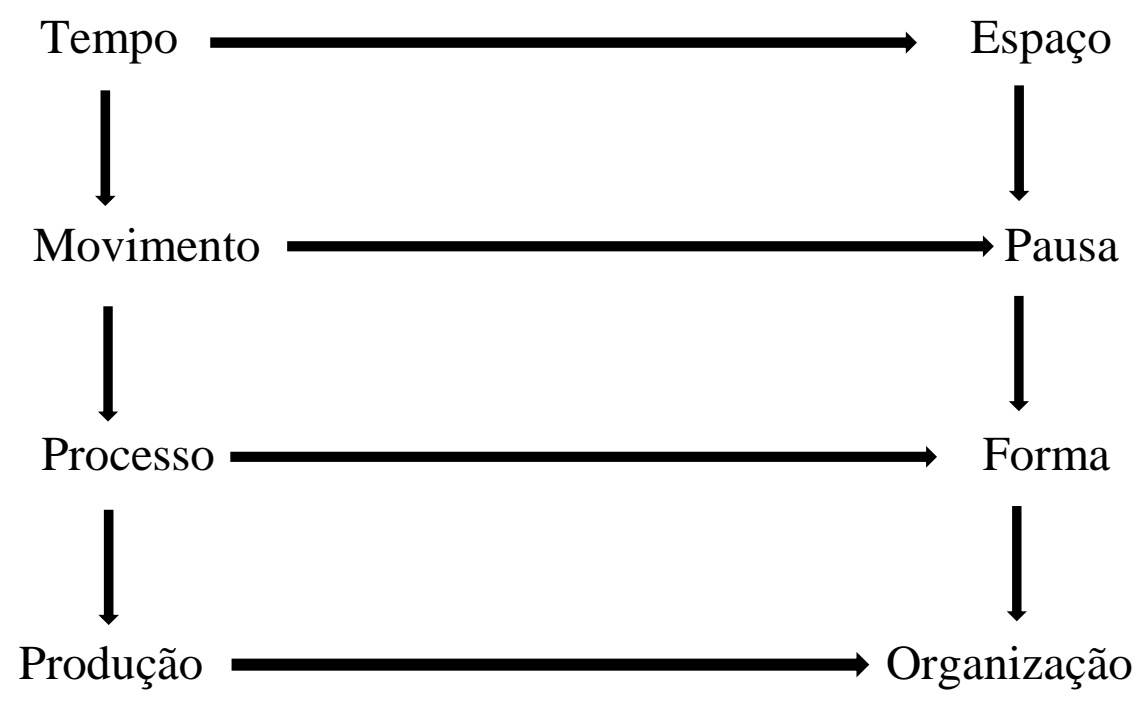

Figura 1. Tempo e Espaço - um esquema

A unidade entre tempo e espaço emerge ao se considerar que tempo é movimento e espaço é pausa. O movimento não é ininterrupto, havendo interrupções, isto é, pausas nas quais criam-se formas, cristalizações. Se o movimento não sofresse interrupções, minúsculas que sejam, não haveria a criação de nada. O movimento é equivalente a processo e este gera forma. Se processo não gerar forma deixa de ser uma possibilidade, não se efetiva. Pois a função básica do processo é a criação de forma. Esta, por sua vez, só pode existir como criação de processo. Em outros termos, o processo gera forma e esta é criada pelo processo. Tempo - Movimento - Processo implica em Produção, enquanto Espaço - Pausa - Forma, por sua vez, implica em Organização. Produção e organização são os dois lados da mesma moeda. Afirmar que um é melhor, superior ao outro é um equívoco. Mas se conceitualmente são inseparáveis, analiticamente podem ser separados, considerando-se que, se há uma unidade entre os dois, permitindo relações entre ambos, há também uma relativa autonomia entre tempo e espaço. Relações e autonomia relativa são propriedades de todos os seres, de qualquer formação material.

\section{Temporalidade e Espacialidade}

Tempo e espaço envolvem processos e formas da natureza e socialmente produzidos. O movimento e a pausa qualificam a existência e reprodução dos processos e formas, permitindo falar em 
temporalidade e espacialidade. Ambos estão inter-relacionados, mas guardam uma relativa autonomia e por isso podem ser analisados separadamente.

a) Temporalidade

A temporalidade diz respeito aos atributos associados ao tempo. Assim, refere-se diretamente ao movimento e aos processos, ainda que relacionando-se à pausa e à forma. $\mathrm{A}$ temporalidade está, assim, manifestando-se na espacialidade. Três atributos podem, ao menos, caracterizar a temporalidade: criação, desenvolvimento e transformação. Não se trata de uma transposição pura e simples de atributos da biologia, especialmente se considerarmos o espaço, visto como locus da ação humana. Em realidade as relações entre tempo social e espaço social são muito complexas, não exibindo uma relação nitidamente linear. Na temporalidade humana há processos de resiliência e regressão que, por sua vez, afetam a espacialidade.

A criação envolve agentes sociais e contexto criativo. Os agentes sociais criam espaços em suas diversas manifestações, isto é, a paisagem, a região, o território, o lugar e as redes. Os agentes sociais são historicamente constituídos, estando inscritos em um dado tempo histórico, ainda que tempos históricos específicos possam coexistir no mesmo tempo e espaço empíricos.

Mercadores de escravos e capitalistas são exemplos distintos, tendo desenvolvido atividades geradoras de espacialidades também distintas. Proprietários fundiários, especialmente os grandes latifundiários, e promotores imobiliários constituem também importantes agentes sociais. As grandes corporações multifuncionais e multilocalizadas e o Estado, por outro lado, também se inscrevem entre os agentes sociais importantes. A força de trabalho, operários, trabalhadores sem terra e empregados do comércio e serviços, deixados de lado na literatura sobre o tema, são também agentes criativos, não por meio do capital, mas do trabalho. A variedade de agentes sociais e a possibilidade, por exemplo, de um industrial se tornar também um proprietário fundiário ou promotor imobiliário, não esgota uma rica e permeável tipologia destes agentes. É importante, no entanto, ressaltar que estes agentes têm interesses variados e mutáveis, exercem práticas espaciais, assim como estabelecem relações entre si. Assim, os agentes sociais não podem ser metamorfoseados via a mão invisível do mercado, esta abstração escamoteadora, nem como o Estado hegeliano, onisciente, onipresente, justo e correto, tampouco como um capital abstrato, genérico, destituído de relações sociais. Também não podem ser desconsiderados as tensões e os conflitos entre agentes, particularmente entre aqueles que detêm poder e aqueles que vendem sua força de trabalho. 
A ação dos agentes sociais se faz em um dado contexto criativo, em um dado genius tempore. A formação social é expressão de um dado tempo histórico espacializado que envolve o desenvolvimento das forças produtivas e das relações sociais, mas é preciso considerar no âmbito de cada formação social a singularidade de cada lugar, favorável ou não à criação por parte dos agentes sociais. Há assim um genius loci. Recursos naturais, tradição cultural e infraestruturas herdadas do passado podem criar possibilidades locais para a ação dos agentes sociais. A natureza das elites locais ou da força de trabalho desempenham papel significativo no processo criativo local.

Movimento pressupõe mudanças nos processos e formas desde a criação à transformação. Tornar inteligíveis estas mudanças tem sido preocupação permanente de filósofos e cientistas. Os geógrafos também se preocupam com as mudanças na organização do espaço e diversas interpretações foram construídas. O debate a este respeito é rico e sugere reflexões sobre as causas, os agentes, os meios e os impactos das mudanças. Mudanças lineares, repetitivas para todos os processos e formas, ou mudanças próprias a cada processo e forma? Os modelos a respeito do desenvolvimento regional, da evolução, dos transportes terrestres e marítimos ou dos mercados periódicos, são exemplos do primeiro tipo de interpretação da mudança, assim como o é a visão a respeito da evolução do uso do solo na cidade capitalista. A esta perspectiva, que tem exercido o interesse do planejamento urbano e regional, opõe-se aquela visão calcada no desenvolvimento próprio a cada processo, forma e lugar, ou seja, a unicidade não repetitível de cada processo, forma e lugar. Às leis e modelos opõe-se a visão excepcionalista, que também se opõe à perspectiva do materialismo histórico e dialético, calcada na concepção do desenvolvimento desigual e combinado, mas que pouco avança no que se refere ao modo como isto se efetivará. De qualquer modo, esta é uma questão em aberto.

Processos e formas exibem um limite no tempo no que tange a sua existência e reprodução. Assim transformam-se, gerando outras formas, ou desaparecem. No que diz respeito à organização do espaço, a transformação é complexa. Resíduos verificados arqueologicamente ou ruínas apontam para transformações que profundamente alteraram a organização do espaço. A memória de grupos sociais distintos revela aspectos seletivos dessa organização espacial; por outro lado, pode incluir uma sobrevida marginal, na qual a inércia garante a existência de formas inseridas marginalmente na sociedade. Cidades mortas, cidades decadentes são exemplares. Os patrimônios históricos, por sua vez, resultam do esforço direcionado a transformações para algo de valor simbólico, muitas vezes reinventando o passado.

A refuncionalização de formas criadas no passado, atribuindo a elas novas funções diferentes daquelas originais, é um modo muito frequente de transformação. Os exemplos são numerosos, como fábricas transformadas em shopping centers ou museus, cinemas transformados 
em templos e estações ferroviárias transformadas também em shopping centers ou museus. resultado é o aparecimento de uma paisagem constituída por formas modernas e antigas, mas com funções modernas.

Criação, desenvolvimento e transformação definem a temporalidade, o tempo em seu movimento. Qual o interesse do geógrafo pelo tempo? Pensamos que o geógrafo pode se interessar pelo tempo ao considerar temas que não são mutuamente excludentes: herança, memória, projeto, inscrição e trajetórias. A herança diz respeito às formas espaciais herdadas do passado, seja por inércia, seja por refuncionalização. As cidades, sobretudo as grandes cidades, exibem áreas que são heranças que falam da história e geografia dessas cidades. A memória refere-se aquilo que está na mente daqueles que viveram o passado. Há várias memórias, todas seletivas. O projeto por sua vez remete-se às obras concebidas e planejadas, mas não executadas. O seu estudo pode sugerir uma visão imaginada do que poderia ser aquela organização do espaço. A inscrição constitui uma análise sincrônica de uma seção do passado considerando a organização espacial de uma dada área. Seria como se fosse uma geografia regional do passado. Uma questão que emerge é a de como estudar essa área no passado. Em uma perspectiva calcada na eucronia, isto é, vendo o passado à luz do passado, ou na perspectiva da anacronia, isto é, vendo o passado à luz do presente, perspectiva que parecer ser mais viável. A trajetória, finalmente, consiste em considerar o percurso que uma dada organização do espaço seguiu desde sua criação. Trata-se de análise diacrônica, longa, que requer o uso de fontes distintas e por vezes não comparáveis. Dois temas aparecem nessa perspectiva. O primeiro é o da difusão espacial, um processo espaço-temporal no qual um item, seja ele econômico, social ou político, espraia-se a partir de um foco inicial. As frentes de povoamento e a expansão de uma dada cultura são exemplos consagrados. O segundo é o da periodização do espaço, um esforço de estabelecer períodos para um dado espaço, uma cidade, uma rede urbana ou uma rua. Os períodos dividem o espaço em tempos relativamente homogêneos, cada período descrevendo a história e a geografia da área sob análise.

b) Espacialidade

A ação humana se realiza sobre um espaço diferenciado, primeiramente pela natureza e em seguida pelo próprio ser humano. Diferenciação espacial é o primeiro conceito associado à espacialidade, que só pode ser pensada no âmbito de um espaço heterogêneo. Em um espaço totalmente homogêneo não é possível falar em espacialidade. Esta, por sua vez, é central para a Geografia, enquanto a temporalidade o é para a História. 
Os elementos que articulados permitam falar em espacialidade são: localização, escala, arranjo espacial e interações espaciais. Todos eles fazem parte da tradição de pesquisa em geografia e podem ser considerados sob diferentes bases teóricas e metodológicas, não havendo em tese nenhuma conexão inequívoca e única entre qualquer um dos quatro elementos apontados e um dada matriz teórica e metodológica.

Localização constitui um dos temas centrais na geografia, havendo numerosos esquemas teóricos sobre localização, seja na agricultura, indústria, comércio e serviços, a cidade e a rede urbana, as diferentes classes sociais e outros aspectos. Desenvolvidas com base no pensamento calcado no positivismo e em teorias econômicas neoclássicas, a localização pode ser considerada sob outras perspectivas e este é um ponto para aprofundamento.

É a partir de uma localização que o ser humano fixa-se, produz e organiza o espaço e estabelece interações espaciais entre localizações. Produto, meio e condição de existência e de reprodução, a localização resulta da ação dos diversos agentes sociais, desde comunidades primitivas às grandes corporações e ao Estado. A localização torna-se, ela própria, objeto de investimentos para fins lucrativos, ingressando assim na esfera da acumulação de capital. Tornase assim, uma mercadoria muito especial, dotada de valor de uso, valor de troca e valor simbólico.

A localização pode ser absoluta, relativa ou relacional. A primeira diz respeito ao local onde uma dada atividade ou o próprio ser humano está fixo. Trata-se do sítio, esta noção tradicional na geografia, definida por uma referência à latitude e longitude ou um endereço formal. Pressupõe a apropriação de um segmento do espaço, via de regra, transformado em propriedade privada. A localização absoluta, por outro lado, é a primeira referência identitária do indivíduo ou da empresa. Mas a localização não se encontra solta no espaço. Vincula-se a uma das vias, caminhos rurais, estradas, ruas e avenidas, estando perto ou longe de praças e entroncamentos. A localização desfruta, assim, de maior ou menor acessibilidade, tendo um caráter relativo. Adicionalmente a localização tem um caráter relacional, isto é, mantém relações com a natureza social de áreas próximas ou distantes. Está no centro, na periferia, em zona de transição ou em um setor de amenidades e de alto nível social ou encravada em uma favela. O caráter relacional da localização define, mais que a localização absoluta, a identidade de seu ocupante, conferindo à localização maior ou menor valor de uso, troca e simbólico.

A localização, adicionalmente, pode ser vista sob outros prismas. Localização residual e localização refuncionalizada são algumas das possibilidades. A primeira refere-se ao fato de que os fatores de localização cessaram, mas as atividades permanecem no local, pois ainda se tornam viáveis naquela localização em virtude da força econômica da atividade ou da impossibilidade de seu ocupante se transferir. A segunda consiste na refuncionalização, isto é, a manutenção de 
formas antigas com novas funções. A refuncionalização do local tem equivalências naquele processo denominado de invasão-sucessão.

A localização pode se associar a um quadro econômico e social de abandono ou de decadência. Trata-se da localização marginalizada, muitas vezes expressa em paisagens ruinoformes. Localização emergente, finalmente, em áreas de expansão do ecúmeno ou área de expansão urbana, constitui um outro tipo de localização, temática sempre promissora para tornar inteligível as complexas e mutáveis relações entre tempo e espaço.

Escala é um termo polissêmico, sendo empregado ora para medir a intensidade de um abalo sísmico, ora para medir a temperatura ou ainda o tempo cronológico, o som da música ou o momento de trabalho de um trabalhador em equipe. Esta polissemia está também presente na geografia. Há uma escala dimensional, cartográfica, espacial e conceitual, todas vinculadas à espacialidade.

A escala dimensional refere-se ao tamanho das formas espaciais, que pode ser absoluto, relativo ou relacional, os dois últimos sendo de natureza comparativa. A escala dimensional pode ser considerada ao se falar em economias internas de escala e economias externas de escala. Empregadas na geografia econômica, a primeira diz respeito, por exemplo, a uma grande usina siderúrgica integrada, que possui coqueria, alto forno, aciaria e unidade produtora de bens a partir do aço. Todas estão na mesma localização e apresentam ganhos por esta integração. Economias externas de escala ou economias de aglomeração criam vantagens para diversas empresas, pequenas, via de regra, e funcionalmente conectadas entre si, beneficiando-se da co-presença na mesma localização. Atividades econômicas situadas tanto à montante quanto à jusante na cadeia produtiva das pequenas empresas garantem vantagens ao conjunto aglomerado. Ruas especializadas no comércio de autopeças, lustres e móveis, por exemplo, exemplificam esse tipo de economia externa de escala.

A escala dimensional também se faz presente nas formas simbólicas espaciais, por exemplo, um templo, uma estátua ou um memorial de guerra, pois exibem poder e marcam a paisagem geográfica. Nas representações cartográficas, os objetos representados aparecem com mais nitidez nos mapas em grande escala. Descrevem eles a espacialidade de modo distinto, o que tem implicações na interpretação do mapa. Local, regional, nacional e global são termos que definem escalas espaciais, envolvendo o alcance com que um objeto projeta a sua ação e seu poder de impactar sobre um dado espaço. $\mathrm{Na}$ interpretação dessas escalas é preciso cuidado com a mudança escalar. A interpretação de um objeto em uma escala nacional não pode ser a mesma quando este mesmo objeto é considerado em escala local. Pode-se incorrer em uma falácia escalar, 
produzindo-se equívocos ao se interpretar a espacialidade humana. Assim, na localização de uma fábrica é preciso considerá-la nas diversas escalas espaciais a que ela está inscrita.

Ao se mudar a escala muda-se o objeto de análise, mudando-se também as bases teóricas e as interpretações do objeto. Nesse sentido, há objetos que só podem ser pensados em uma específica escala. Um excelente exemplo é a rede urbana, de um lado, e o espaço urbano, de outro. Trata-se da escala conceitual que nos alerta sobre os riscos de interpretações fora de uma escala pertinente.

Arranjo espacial é o conjunto de localizações disposto sobre a superfície terrestre, seja uma cidade, uma região ou todo um país. Como conjunto descreve a organização espacial, constituindo uma complexa forma espacial, resultado de longos e também complexos processos. Espacialidade e temporalidade estão presentes no arranjo espacial, porém por meio de diversas espacialidades específicas a cada forma e de diversas temporalidades que coexistem no mesmo espaço. Deste modo o arranjo espacial constitui importante temática para a pesquisa geográfica. Ressalte-se que a análise do arranjo espacial não pode ser vista como pura morfologia, a ser ingenuamente analisada de modo descritivo. Trata-se de uma análise da produção/organização do espaço na qual processo e forma estão conectados, assim como movimento e pausa e assim, tempo e espaço.

O arranjo espacial pode ser visto segundo diferentes ângulos. Concentrado ou disperso é um deles. A concentração espacial, assim identificada segundo uma dada escala espacial, significa alta densidade de formas espaciais e de economias de escala no espaço. Os efeitos desta concentração podem ser positivos ou negativos, ou ambos. A concentração é, em realidade, objeto de ação da esfera pública, estando associada a vários modelos e teorias interpretativas e visando a ação. A dispersão, por outro lado, também assim identificada segundo uma dada escala espacial, resulta da escassez de fatores locacionais que não permitem a concentração, entre eles água e solo, mas também o modo como um grupo social se apropria e organiza o espaço. A dispersão, como a concentração, é também objeto de políticas públicas.

Concentração e dispersão podem constituir arranjos espaciais contínuos ou descontínuos, segundo processos distintos de apropriação generalizada ou seletiva do espaço. As razões podem ser complexas, mas a temática é significativa para tornar inteligível a organização/produção do espaço. O arranjo espacial pode ainda se apresentar em área ou linha que exibem diferentes formas, a exemplo da 'linha colonial', do 'tabuleiro em xadrez' ou apresentar-se de modo aleatório. A pesquisa geográfica, a este respeito, tem há longo tempo evidenciado padrões espaciais de povoamento rural ou urbano, que se traduz em arranjos urbanos 'na boca da mata' ou em fundo de estuários, por exemplo. 
Os arranjos espaciais são mutáveis, exibindo uma dada permanência. A espacialidade é assim mutável. Vejam-se, por exemplo, as cidades 'boca de sertão' ou 'ponta de trilhos' ou, ainda, cidades decadentes que se localizam junto às minas tornadas improdutivas. Em resumo, arranjo espacial é tradicional e importante tema de análise da espacialidade.

As interações espaciais constituem os elos que conectam as diversas localizações. Estas têm a sua existência e reprodução garantidas pelas interações, que assim garantem as relações econômicas, políticas e sociais da sociedade. Parte integrante da espacialidade, as interações espaciais, por outro lado, estão também inscritas na temporalidade, inscritas em um dado genius tempori, manifesto em embarcações a vela, tropas de burros de carga, diligências, navios a vapor e ferrovias, assim como no rádio, televisão, aviação e os modernos equipamentos de informática, e naquilo que o futuro nos reservará, tornando as redes geográficas mais densas e muito mais complexas que atualmente, com múltiplos circuitos, sejam materiais ou não. A distância adquire novos significados.

As interações espaciais são complexas, passíveis de análise por meio de diversos aspectos, entre eles distância, direção, intensidade, frequência, ritmo e itinerário. Estes aspectos impactam sobre a espacialidade, podendo garantir a permanência ou a mudança das localizações, da escala espacial e dos arranjos espaciais. Como reflexo, meio e condição social, as interações espaciais constituem, de per si, importante tema para investigação geográfica, particularmente no âmbito das transformações que a tecnologia informacional tem induzido, visando a aniquilação do espaço pelo tempo, uma agenda cada vez mais presente na sociedade capitalista.

As interações espaciais são tema de enorme importância para pesquisa geográfica. A temática das redes geográficas, isto é, localizações articuladas entre si por vias e fluxos, inscreve as interações espaciais no âmbito da localização, da escala e dos arranjos espaciais. A teoria dos lugares centrais, em suas versões despidas de formalismo, é talvez o melhor exemplo. Mas há muito mais, como os estudos sobre fluxos de mercadorias, pessoas, ideias e capital. A espacialidade do ciclo de reprodução do capital, por mais complexo que seja, constitui tema para estudos de organizações corporativas. A jornada para o trabalho, os deslocamentos para compras e lazer são outros exemplos, assim como as migrações e os deslocamentos realizados em itinerários simbólicos, a exemplo de peregrinações, procissões, paradas militares e marchas de protesto. 


\section{Considerações Finais}

Temporalidade e espacialidade, isto é, tempo e espaço, estão fortemente interconectados. Assim, o processo de criação manifesta-se em localizações diferenciadas, em diversas escalas, em vários arranjos espaciais e complexas interações espaciais. Do mesmo modo, um dado arranjo espacial resulta de um processo de criação, apresentando um dado caminho de desenvolvimento, vindo a exibir uma dada transformação. Significa dizer que criação, desenvolvimento e transformação, de um lado, e localização, escala, arranjo espacial e interações espaciais, de outro, estão interconectados entre si, ainda que desfrutem, cada um, de relativa autonomia. As interconexões são complexas, dotadas de uma dialética, e devem ser objeto de inúmeras análises. Este breve ensaio procurou refletir sobre aspectos fundamentais envolvendo tempo, espaço e geografia. 